\title{
Complex Endometrial Hyperplasia without Atypia
}

National Cancer Institute

\section{Source}

National Cancer Institute. Complex Endometrial Hyperplasia without Atypia. NCI

Thesaurus. Code C6993.

A hyperplasia characterized by excessive proliferation of endometrial cells, resulting in the formation of complex epithelial structures. Epithelial atypia is absent. 